\title{
Understanding Users' Preference to Engage in YouTubers
}

\author{
Wen-Yu Tsao \\ Department of Information Management, \\ National Chin-Yi University of Technology, Taiwan, R. O. C. \\ No.57, Sec. 2, Zhongshan Rd., Taiping Dist., Taichung 41170, Taiwan (R.O.C.) \\ E-mail: tsaowy@ncut.edu.tw
}

Received: Jan. 14, 2019 Accepted: Feb. 13, 2019 Online published: Feb. 17, 2019

doi:10.5296/ijhrs.v9i1.14357～URL: https://doi.org/10.5296/ijhrs.v9i1.14357

\begin{abstract}
The YouTubers are the new vocations to make money. People like to access the videos to relax or learn from the special YouTuber. Despite the growth and commercial potential of virtual worlds, relatively little is known about what users' motivations to favor specific YouTubers. This paper offered and empirically tested a conceptual model to fill this gap. Given the system characteristics (mobility, reachability, compatibility, convenience) and YouTuber specific characteristics (escapism and post popularity) integrated extrinsic and intrinsic motivation as their preference determinants. Using PROCESS on a survey of 349 users of YouTube. The results confirmed the role of extrinsic and intrinsic motivation as preference determinants and showed the two system and two YouTuber specific characteristics as motivational basis. Implications for research and practice are discussed.
\end{abstract}

Keywords: motivation theory; system and YouTuber specific characteristics; preference

\section{Introduction}

Internet usage involves the sales or presentations of goods, services, and contents via the Internet, without time or space limitations (Mallat, 2007; Au \& Kauffman, 2008; Kim et al., 2010). According to a survey on the wireless Internet usage in Taiwan (2017), the three most used platforms for live broadcast service are Facebook (68.0\%), YouTube (41.5\%), and Twitch (6.9\%) (https://www.twnic.net.tw/download/200307/200307index.shtml); this shows that YouTube is a popular platform. YouTube is a natural platform for anyone to present ideas or thoughts, and it makes it feasible and convenient for Internet users to access videos. Because of this convenience, the platform is becoming increasingly more popular. In this study, a "YouTuber" is defined as any person or group who uses YouTube platform to share experiences on new ideas (Ramos-Serrano \& Herrero-Diz, 2016), or to gain viewers 
(McRoberts et al., 2016), or to earn money with their videos (Westenberg, 2016).

Because YouTube is a free platform that allows Internet users to upload and download videos quickly and directly (Correa et al., 2010), many Internet users want to be YouTubers to become famous and make a fortune; however, only few of them achieve this. According to Mathwick et al. (2001) defined preference as the YouTube video attributes most favoured by Internet users. This preference is affected by several factors, which have not been adequately studied in the literature. Considering the current state of the existing research on YouTubers, the purpose of this study is to empirically assess the determinants of YouTubers preferences by users. To achieve this, a research model is proposed, which consists of two system characteristics, YouTuber specific characteristics, and two motivations for user preference. The motivation theory is a well-recognized model used for predicting information technology (IT) usage (Ryan \& Deci, 2000a, b). According to the motivation theory, Verhagen et al. (2012) stated that entertainment value and perceived usefulness are intrinsic and extrinsic motivations, respectively, needed to engage users in a virtual world. According to Ryan \& Deci $(2000 a, b)$ redefined intrinsic motivation as watching the videos from the YouTuber for the inherent satisfaction of itself and extrinsic motivation redefined as watching the videos from the YouTuber leads to a separable outcome. The latter determined by mobility, reachability, compatibility, and convenience of system characteristics (Kim et al., 2010) which both motivations are determined by escapism of YouTuber specific characteristics (Verhagen et al., 2012). One major benefit of using the motivation theory is that it provides a framework by which the effect of intrinsic and extrinsic motivations of users on IT can be used to assess user positive preference (Mathwick et al., 2001). To adopt the motivation theory in the YouTubers context in this study, it is integrated with four system characteristics and two YouTuber specific characteristics. Moreover, to better understand user preference, the mediating effect of the entertainment value (intrinsic motivation) was tested.

This paper would be contributed to maintain a series of chains in YouTube, such as merchants who buy ad., advertisers who create ad., mobile network designers who design the network accessible, maintainers who debug the problems, YouTubers who provide appropriate videos to make people relax or share knowledge, and users who watch the videos to fit new requirements and solve problems. The remainder of the paper is arranged as follows: Section 2 presents the literature review, focusing on the motivation theory and YouTube user preferences. Section 3 presents the research model and hypotheses. Section 4 provides a data analysis of the survey results. In Section 5, the results, as well as the summary, contributions, implications, and limitations of the study, are discussed.

\section{Literature Review}

In this section, a theoretical background of this study is developed, considering the system characteristics, YouTuber specific characteristics, motivation theory, and preference.

\subsection{System Characteristics and YouTuber Specific Characteristics}

The overall user preference about interacting with the system based on the system characteristics and the YouTuber specific characteristics is considered to be a vital 
determinant of the system usage. According to user experience, information technologies have been classified based on their usefulness (Kim et al., 2010) and the enjoyment they provide (Verhagen et al., 2012). Kim et al. (2010) attributed user acceptance of mobile payment to the following system characteristics: mobility, reachability, compatibility, and convenience. The mobility and reachability were defined as the feelings of users regarding the portability (Park et al., 2015) and connectivity of a specific device. Considering that YouTube videos are free to view, perceived convenience and compatibility are defined based on videos characteristics such as reacting quickly and positively, ease of usage, and well-matching and well-suited temporally and geographically (Dong et al., 2017). These characteristics consequently determine the perceived usefulness (Kim et al., 2010). Therefore, in this study these characteristics are included as factors affecting in the YouTuber videos of users' preferences. On the other hand, according to Henning \& Vorderer (2001), escapism is defined as the extent to which users become engaged by watching videos from specific YouTuber that their desires to be absent from reality are fulfilled. Escapism is an important system-specific virtual world characteristics of IT value and motivation theory that affects both perceived usefulness (extrinsic motivation) and entertainment value (intrinsic motivation) regarding virtual world usage. Post popularity is measured by the number of likes, shares, and response comments on posts (De Vriesa et al., 2012). For example, the number of likes and comments, shares, and response comments specific YouTuber videos. Therefore, in this study, escapism and post popularity are classified as YouTuber specific characteristics. Perceived usefulness is defined as the users' perceptions that are derived from personal inferences about the relieving or educative benefits of videos (Bhattacherjee \& Sanford, 2006; Verhagen et al., 2012). Entertainment value can be regarded as the degree to which IT usage is a fun, pleasant, and encouraging experience, i.e., the degree to which users perceive the videos from the specific YouTuber would relieve or inform them. Post popularity directly affects perceived usefulness and preference in social media marketing (Chang et al., 2015). Therefore, in this paper, the system characteristics and YouTuber specific characteristics are combined to analyse the factors affecting perceived usefulness and preference.

\subsection{Motivation Theory}

Many researchers have used the motivation theory to predict IT usage (Deci \& Ryan, 1985; Vallerand, 1997; Ryan \& Deci, 2000a, b). Motivations are classified into intrinsic and extrinsic motivations (Grant, 2004). Ryan \& Deci (2000b) described extrinsic motivation as "doing something because it leads to a separable outcome," and Ryan \& Deci (2000a) described intrinsic motivation as "doing an activity for the inherent satisfaction of the activity itself." In IT research, intrinsic motivation is seen as a strong predictor of hedonic system usage (Venkatesh, 1999). Intrinsic motivation arises from the intrinsic value of the work or the derived leisure (e.g., excitement or pleasure), whereas, extrinsic motivation arises from the desire to obtain some goals (e.g., an outcome that could be used for relaxation or learning) that are apart from the action itself (Amabile, 1993; Verhagen et al., 2012). As opposed to extrinsic motivation, intrinsic motivation arises from the satisfaction of the activity itself rather than its outcome (Mathwick et al., 2001). In this study, intrinsic and extrinsic motivations for YouTuber usage are considered natural. This inference rests on the evidence 
that users watch the videos from YouTubers to satisfy a need. Intrinsically motivated behavior involves users engaging in activities that they find interesting, fun, and optimally challenging (Deci \& Ryan, 1985). In this study, these two types of motivation are seen as the key determinants of watching videos from YouTubers. In IT research, intrinsic motivation is a better predictor of extrinsic motivation in usage (Venkatesh, 1999). In line with motivation theory, the mainstay of the proposed research model includes the perceived usefulness and entertainment values corresponding to extrinsic and intrinsic motivations, respectively. Few scholars have tested both types of motivation in YouTubers usage studies and they all ignore the relationships between motivation and preference, implying that the motivation theory is vital to the phenomena.

\subsection{Preference}

Preference for a particular product means a high possibility of choosing such one (Johnson, 1980). Preference is defined as the positive feelings of users toward a product or activity, such as Internet and local in-store retail for shopping products (Mathwick et al., 2001). Joiner (2001) said that employee was preference for clear unambiguous instruction from management to get less risk-taking. The perceived usefulness and preference of users are two main factors that affect their engagement in virtual world, where preference includes favourable feelings and interests (Kim \& Son, 2009). The perceived usefulness and escapism of users affect their entertainment value in virtual worlds (Verhagen et al., 2012) and preferences in social media marketing (Chang et al., 2015). Verhagen et al. (2012) verified that users' perceptions of usefulness and entertainment value affected their attitude in the virtual world scenario, however, Hsu \& Lin (2008) pointed out that users' attitudes were their preferences when carrying out an activity such as blogging. Therefore, users' perceptions of usefulness and entertainment value affected their preferences. According to Bhattacherjee \& Sanford (2006), perceived usefulness refers to the users' personal or professional judgments about the degree to which the videos from YouTubers would relieve or enlighten them. Users' perceptions of the usefulness of the post affects preferences toward IT usage (Bhattacherjee \& Premkumar, 2004). Therefore, in this study, preference is considered with regards to the motivation theory.

\section{Methodology}

\subsection{Research Model}

From previous research, two principal categories of external variables-system characteristics and YouTuber specific characteristics- have been identified as major factors of the motivation theory. The proposed research model comprised four factors of the system characteristics, two YouTuber specific characteristics, two motivations, and users' preferences of the YouTuber, showed as Figure 1. 


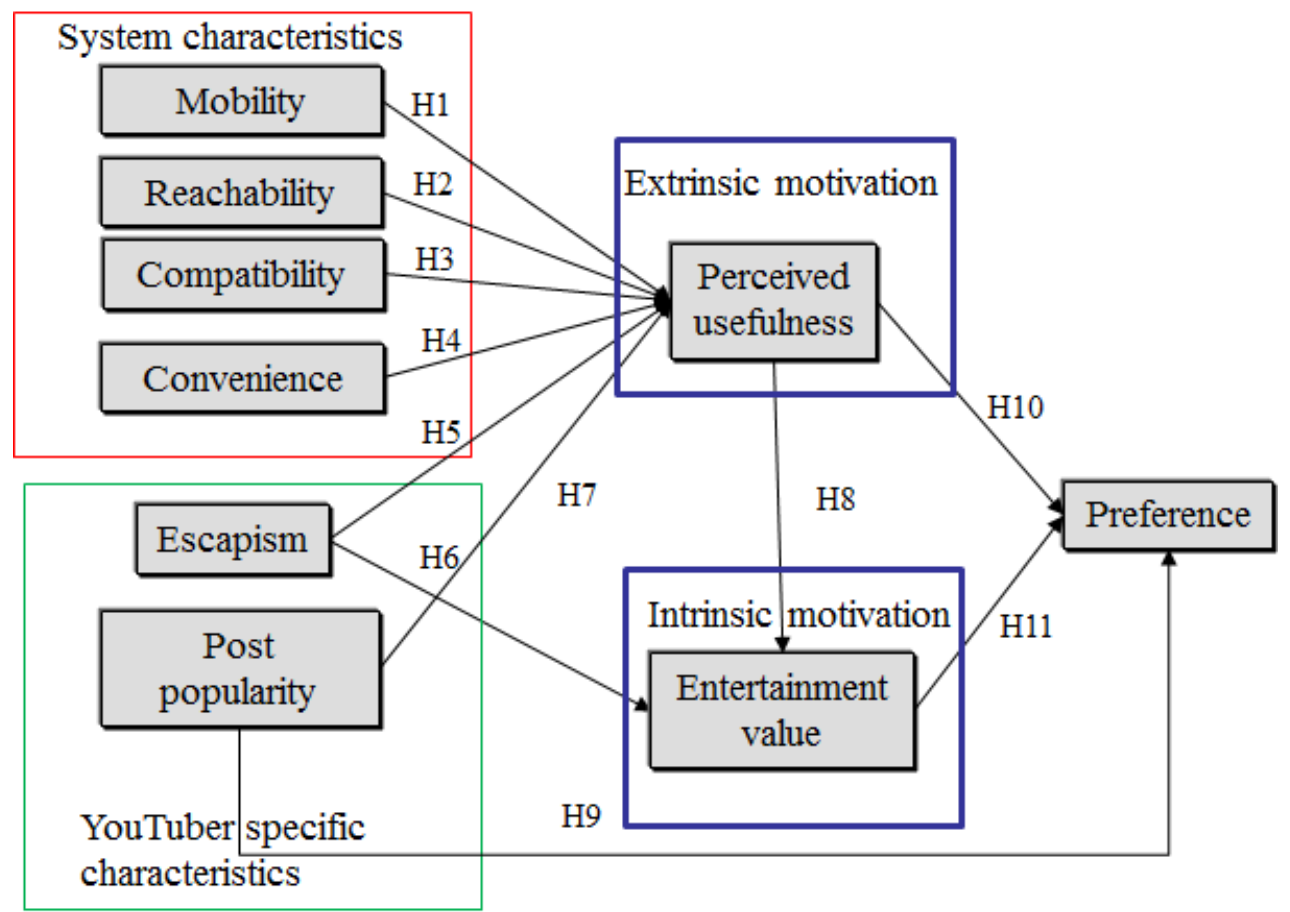

Figure 1. Research Model

\subsection{Hypotheses}

System characteristics (Davis et al., 1989) have the potential to directly affect the perceived usefulness of IT which is classified as an extrinsic motivation (Verhagen et al., 2012). In previous studies involving system characteristics, it has been suggested that external factors such as mobility, reachability, compatibility, and access convenience have strong relationships with the perceived usefulness of mobile payment (Kim et al., 2010). Mobility allows all devices, protocols, and infrastructures to transform and exchange information from one to many, irrespective of time and place (Lim, 2007). Trakulmaykee et al. (2013) investigated the mobility-influenced perceived usefulness in mobile tourism guide. Yen \& Wu (2016) predicted the adoption of mobile financial services and found that mobility significantly impacted on perceived usefulness. Hossain et al. (2018) also employed mobility as a metric to predict Bangladeshi customers' perceived usefulness of mobile payment. Li et al. (2014) proved mobility and compatibility as the factors driving the perceived usefulness and thus adoption of NFC-enabled mobile payment. Other results indicate the importance of usefulness and system characteristics such as mobility, reachability, compatibility, and convenience (Daskapan et al., 2010; Kim et al., 2010; Verhagen et al., 2012; Smith \& Sankaranarayanan, 2012; Yang et al., 2012; Arvidsson, 2014; Zhou, 2014; Teo et al., 2015). In this study, it is considered that the mobility, reachability, compatibility, and convenience characteristics of videos from the YouTuber affect users' perceived usefulness. Therefore, the following hypotheses are proposed:

H1. The mobility characteristic of videos from the YouTuber positively affects the perceived usefulness.

H2. The reachability characteristic of videos from YouTuber positively affects the perceived 
usefulness.

H3. The compatibility characteristic of videos from YouTuber positively affects the perceived usefulness.

H4. The convenience characteristic of videos from YouTuber positively affects the perceived usefulness.

Escapism is a special characteristic of Internet that allows users temporarily escape reality (Huizinga, 1955) by using avatars (Gilbert et al., 2011), playing online game (Xu et al., 2012), shopping online (Perea y Monsuwé et al., 2004; Asraar Ahmed, 2015), and learning online (Siklander et al., 2017). It has a specific hedonism characteristic since it mentally relieves users (Hirschman, 1983; Verhagen et al., 2012). Users may escape from reality when they are much occupied with YouTuber' videos. In other words, users watch the videos to lose track of time and appear to be in another world (Mathwick et al., 2001; Saade \& Bahli, 2005; Kim \& Kim, 2005). A system that provides escapism can be viewed as a useful tool to relieve users (Verhagen et al., 2012). Escapism does not only influence perceived usefulness but also influences the entertainment value of a virtual world (Jung and Kang, 2010). Users can become occupied by a YouTuber video and escape from their anxieties or boredom. In this paper, escapism is considered as a YouTube specific characteristic that affects perceived usefulness (extrinsic motivation) and entertainment value (intrinsic motivation). Therefore, the following hypotheses are proposed:

H5. The escapism characteristic of special YouTuber positively affects the perceived usefulness (extrinsic motivation).

H6. The escapism characteristic of special YouTuber positively affects the entertainment value (intrinsic motivation).

According to the motivation theory, extrinsic actions are likely to enhance users' intrinsic motivation (Ryan \& Deci, 2000a, b). Verhagen et al. (2012) found that for most users, the perceived usefulness of virtual worlds positively influenced the entertainment value. Zhang et al. (2014) conducted investigations to understand the usefulness-influenced entertainment value of 3D social virtual world in China. Chang et al. (2015) showed that perceived usefulness influenced preference in social media marketing. Consequently, in this study, it is considered that perceived usefulness, which is an extrinsic motivation, would influence the entertainment value (intrinsic motivation) of the videos. Therefore, the following hypothesis is proposed:

H8. The perceived usefulness (extrinsic motivation) of YouTubers' videos positively affects the entertainment value (intrinsic motivation).

Post popularity is measured by the number of likes, comments, shares, and response comments on posts (De Vriesa et al., 2012), such as the videos from a specific YouTuber. According to Bhattacherjee \& Sanford (2006), the perceived usefulness of posts, as regards relieving or educative benefits, is related to the perceptions derived from personal or professional judgments of such posts. Users judge specific YouTuber videos based on the 
relief or information gained from watching. Sinclair et al. (2010) found that online messages popularity directly affected perceived usefulness. Preference encompasses favorable feelings and interests (Kim \& Son, 2009). Users' post popularity directly affected usefulness and preference in social media marketing, where perceived usefulness influences preference in advance (Chang et al., 2015). It has been found that comments and responses in online reviews affect perceived usefulness and preferences (Park \& Kim, 2008; Bhattacherjee \& Premkumar, 2004). As regards shopping, the perceived entertainment value determined the preferences for offline (Cronin et al., 2000) and for online shopping (Overby \& Lee, 2006). Therefore, particularly for YouTubers' videos, post popularity does not contribute only to the perceived usefulness but also to user preferences. Therefore, the following hypotheses are proposed in this study:

H7. The post popularity YouTuber characteristic of videos positively affects perceived usefulness (extrinsic motivation).

H9. The post popularity YouTuber characteristic of videos positively affects user preference.

H10. The perceived usefulness (extrinsic motivation)of the videos positively affects the user preference.

H11. The entertainment value (intrinsic motivation) of the videos positively affects the user preference.

Wong \& Dean (2009) found that customers' perception of value influences loyalty for both department store and supermarkets. In one study, Wang (2013) found that the perceived value of food product had a full mediating effect on brand preference. Therefore, particularly in YouTuber' videos, entertainment value would have mediating effects on preference. The following hypothesis is proposed:

H12. From escapism and perceived usefulness, the entertainment value of YouTube videos has mediating effects on preference.

\subsection{Instrument Development}

In this paper, a novel model of the relationships among the system characteristics (mobility, reachability, compatibility, and convenience), two YouTuber specific characteristics (escapism and post popularity), two motivations (perceived usefulness and entertainment), and preference is developed. The questionnaire used in the study contained nine constructs that were adopted and modified from prior studies to fit the scope of a web-based survey research form. Participants agreed to answer with statements using a 7-point Likert-type scale (with 1 being "strongly disagree" and 6 being "strongly agree") without "no comment" for forced scaling. Questions regarding mobility, reachability, compatibility, convenience, and perceived usefulness with all three items, were adopted to indicate the degree of user feelings about YouTuber' videos; these items were modified from the items of Kim et al. (2010). Items evaluating escapism (four items) and entertainment value (three items) were adopted to determine the degree of user feelings toward YouTuber' videos; these items were modified from those of Verhagen et al. (2012). Questions regarding post popularity (three items) and 


\section{Macrothink}

International Journal of Human Resource Studies

ISSN 2162-3058 2019, Vol. 9, No. 1

preference (three items) were adopted to indicate the degree of user feelings of YouTuber' videos; these questions were modified from those of Chang et al. (2015). The survey items are shown in the Appendix.

\subsection{Pretest and Pilot Test}

The first version of this survey was later refined via pretesting with 25 experienced graduates in Chin-Yi University of Technology about the study on using YouTube videos. The instrument was then further pilot-tested with 50 experienced undergraduates. The result of the multiple constructs presented a significant degree of refinement and restructuring of the survey instrument to establish the initial face validity and internal validity (Nunnally \& Bernstein, 1994).

\section{Data Analysis}

This section comprises sample data description; assessments of reliability and convergent and discriminant validity; and analysis with PROCESS 3.0 to evaluate the hypotheses.

\subsection{Sample Data Description}

The sample data were collected through a web survey of 349 respondents. The survey was conducted for nine months from January 1 to September 30, 2017 in Taiwan at www.mysurvey.com.tw/YouTubers. Three assistants were hired to link the web survey and analysis with SPSS. The gender-based respondents' ratios were $48.1 \%$ males and $51.9 \%$ females. Approximately $65.6 \%$ of the participants were $21-30$ years old. The majority of responses were the young. Considering education level, most of the respondents were in college $(33.5 \%)$, and considering occupation, most worked in the information industry (25.5\%). The participants' monthly incomes can be summarized as follows: $37.5 \%$ had a monthly income between NT\$20k and 40k. The participants' two most YouTuber preferred YouTubers were auntie_cai $(44.8 \%)$ and a_god (46.0\%), as obtained from a multiple choice assessment. The total percentage of observations was $175.2 \%$ which exceeds $100 \%$, indicating that each respondent in the multiple choice assessment answered 1.75 options on average, especially for no special like $(39.0 \%)$. This is possibly because YouTube is an open platform and easily accessible by everyone; therefore, every YouTube user has many choices. The details are given in Table 1. 


\section{Mll Macrothink \\ International Journal of Human Resource Studies \\ ISSN 2162-3058 2019, Vol. 9, No. 1}

Table 1. Demographic outline of respondents

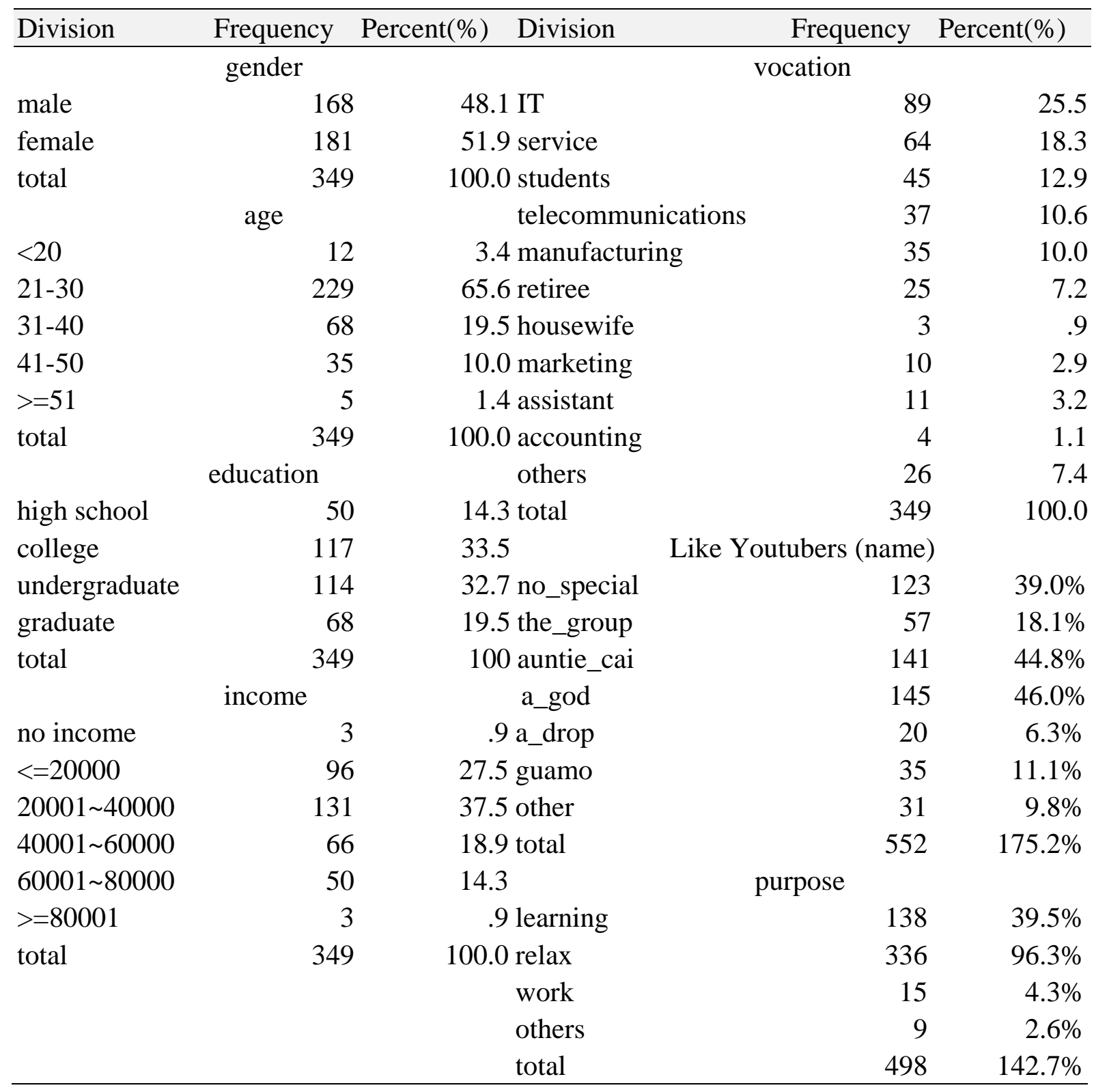

\subsection{Reliability and Validity}

The convergent and discriminant validity of the constructs were tested using principal component analysis with varimax rotation. The Kaiser-Meyer-Olkin measure of sampling adequacy was found to be 0.884 . Thus, the application of factor analysis was appropriate. According to Hair et al. (1998), to determine the minimum items to each construct, items loadings were greater than 0.6. The initial analysis suggested that nine constructs could be extracted, and thus, varimax rotation with factor loadings was then generated. The eigenvalues of the nine constructs were greater than 1.0, and the nine constructs accounted for approximately $75.638 \%$ of the total variance. The Cronbach's alpha of the constructs exceeded 0.7 which is the recommended minimum for the reliability test in social science studies (Nunnally \& Bernstein, 1994). The reliability values were as follows: Mobility (0.926), reachability (0.832), compatibility (0.527), convenience (0.728), escapism (0.892), 
post popularity (0.883), perceived usefulness (0.949), entertainment value (0.842), and preference (0.899). According to Sethi \& King (1994), a construct is acceptable when its reliability exceeds 0.5 . The reliability of compatibility, though less than 0.7 , is acceptable. The first factor explains less than half of the variance (31.124\%) even where common method bias does not exist in reality (Ylitalo, 2009). The composite reality (CR) and average variance extracted (AVE) values of the study constructs were as follows: Mobility (0.896, $0.743)$, reachability $(0.862,0.678)$, compatibility $(0.742,0.500)$, convenience $(0.825,0.611)$, escapism $(0.888,0.728)$, post popularity $(0.844,0.576)$, perceived usefulness $(0.909,0.770)$, entertainment value $(0.854,0.541)$, preference $(0.831,0.622)$. The CR and AVE of the constructs exceed the suggested thresholds of 0.6 and 0.5 , respectively; this indicates that the convergent validity of the proposed model is reliable and acceptable (Fornell \& Larcker, 1981). Reliability confirms internal consistency, and validity ensures convergent and discriminant validity. The details, which include the mean, standard deviation, factor loading, reliability, CR, and AVE, are given in Table 2.

Table 2. Results for overall measurement model $(\mathrm{n}=349)$

\begin{tabular}{|c|c|c|c|c|c|c|}
\hline items & mean & std. & factor loading & alpha & $\mathrm{CR}$ & AVE \\
\hline Mobility1 & 4.178 & 1.084 & 0.880 & 0.926 & 0.896 & 0.743 \\
\hline Mobility2 & 4.266 & 1.064 & 0.892 & & & \\
\hline Mobility3 & 4.473 & 0.933 & 0.829 & & & \\
\hline Reachability1 & 4.960 & 0.909 & 0.713 & 0.832 & 0.862 & 0.678 \\
\hline Reachability2 & 4.948 & 0.886 & 0.883 & & & \\
\hline Reachability3 & 5.034 & 0.780 & 0.866 & & & \\
\hline Compatibility 1 & 2.986 & 1.338 & 0.569 & 0.527 & 0.742 & 0.500 \\
\hline Compatibility 2 & 3.080 & 1.179 & 0.757 & & & \\
\hline Compatibility 3 & 4.226 & 1.242 & 0.768 & & & \\
\hline convenience1 & 4.364 & 1.084 & 0.743 & 0.728 & 0.825 & 0.611 \\
\hline convenience2 & 3.865 & 1.294 & 0.787 & & & \\
\hline convenience 3 & 3.759 & 1.220 & 0.820 & & & \\
\hline Post popularity 1 & 4.923 & 0.771 & 0.763 & 0.883 & 0.844 & 0.576 \\
\hline Post popularity2 & 4.908 & 0.818 & 0.727 & & & \\
\hline Post popularity3 & 4.968 & 0.774 & 0.790 & & & \\
\hline Escapist1 & 5.140 & 0.707 & 0.805 & 0.892 & 0.888 & 0.728 \\
\hline Escapist2 & 4.771 & 0.857 & 0.745 & & & \\
\hline Escapist3 & 4.547 & 0.951 & 0.916 & & & \\
\hline Escapist4 & 4.461 & 0.984 & 0.913 & & & \\
\hline usefulness 1 & 5.146 & 0.734 & 0.881 & 0.949 & 0.909 & 0.770 \\
\hline usefulness2 & 5.020 & 0.800 & 0.879 & & & \\
\hline usefulness3 & 5.089 & 0.785 & 0.884 & & & \\
\hline Entertainment1 & 3.888 & 1.180 & 0.671 & 0.842 & 0.854 & 0.541 \\
\hline Entertainment2 & 4.198 & 1.266 & 0.817 & & & \\
\hline Entertainment3 & 4.716 & 0.911 & 0.700 & & & \\
\hline preference1 & 4.361 & 1.178 & 0.674 & 0.899 & 0.831 & 0.622 \\
\hline preference2 & 4.378 & 1.114 & 0.816 & & & \\
\hline preference3 & 5.063 & 0.653 & 0.756 & & & \\
\hline
\end{tabular}




\section{Mll Macrothink}

Note 1 loading factor $>0.6$ 2019, Vol. 9, No. 1

Note 2 std. means standard deviation

Note $3 \mathrm{CR}($ Composite reliability $)=(\Sigma \text { standardized loading })^{2} /(\Sigma \text { standardized loading })^{2}+$ $\Sigma \varepsilon j$.

Note 4 AVE (Average variance extracted) $=\Sigma$ (standardized loading $\left.{ }^{2}\right) / \Sigma$ (standardized loading $)^{2}+\sum \varepsilon j$

where $\varepsilon j$ - Indicator measurement error

Furthermore, the discriminant validity with correlation analysis were tested, as shown in Table 3. The coefficients of correlation were sufficiently less than 0.7 . The square root of AVE for each construct exceeded its corresponding correlation coefficients with other factors, indicating an acceptable discriminant validity (Fornell \& Larcker, 1981).

Table 3. Correlation estimates with square root of AVE

\begin{tabular}{lccccccccc}
\hline \multicolumn{1}{c}{ dimensions } & 1 & 2 & 3 & 4 & 5 & 6 & 7 & 8 & 9 \\
\hline 1 Mobility & 0.862 & & & & & & & & \\
2 Reachability & $.170^{* *}$ & 0.823 & & & & & & & \\
3 Compatibility & .014 & -.058 & 0.703 & & & & & & \\
4 Convenience & $.329^{* *}$ & $.349^{* *}$ & $.116^{*}$ & 0.782 & & & & & \\
5 Escapism & $.509^{* *}$ & $.228^{* *}$ & .040 & $.234^{* *}$ & 0.759 & & & & \\
6 post & $.229^{* *}$ & $.237^{* *}$ & -.008 & $.255^{* *}$ & $.405^{* *}$ & 0.853 & & & \\
7 usefulness & $.307^{* *}$ & $.426^{* *}$ & .075 & $.336^{* *}$ & $.372^{* *}$ & $.228^{* *}$ & 0.877 & & \\
8 Entertainment & $.315^{* *}$ & $.234^{* *}$ & $.234^{* *}$ & $.348^{* *}$ & $.434^{* *}$ & $.357^{* *}$ & $.309^{* *}$ & 0.736 & \\
9 preference & $.471^{* *}$ & $.215^{* *}$ & .052 & $.321^{* *}$ & $.600^{* *}$ & $.499^{* *}$ & $.429^{* *}$ & $.441^{* *}$ & 0.789 \\
\hline
\end{tabular}

Note 1. **: $\mathrm{p}<0.01 ; *: \mathrm{p}<0.05$

Note 2. the diagonal bold means square root of AVE

\subsection{Analysis and Results}

To determine the effects of system characteristics, YouTuber specific characteristics, and motivation theory on YouTuber preferences, PROCESS, which is a path analysis computational tool, was used to describe the mediation and moderation analysis as well as their combination in the form of a "conditional process model." According to Hayes \& Preacher (2014) and Hayes (2018), PROCESS is a path analysis calculation tool based on mediation and moderation, and proposes models constructed 92 models. In this study, the fourth model in PROCESS 3.0 was used to identify the mediating effects. Then a bootstrapping technique (Preacher \& Hayes, 2004) was used to test these effects. The data were resampled 5000 times to estimate the confidence intervals of the mediated effects. The significance of the bootstrap data was interpreted by determining whether zero was contained within the $95 \%$ confidence interval (CI), where zero is considered to be non-significant. 


\section{Macrothink}

International Journal of Human Resource Studies

ISSN 2162-3058 2019, Vol. 9, No. 1

The results indicated that users felt that the mobility $(\beta=0.088, \mathrm{t}=1.895, \mathrm{p}>0.05)$, reachability $(\beta=0.315, \mathrm{t}=6.350, \mathrm{p}<0.001)$, compatibility $(\beta=0.068, \mathrm{t}=1.469, \mathrm{p}>0.05)$, convenience $(\beta=0.133, t=2.568, p<0.05)$ of system characteristics as well as escapism $(\beta$ $=0.212, \mathrm{t}=3.743, \mathrm{p}<0.001)$, and post popularity $(\beta=0.012, \mathrm{t}=0.234, \mathrm{p}>0.05)$ of the videos from YouTuber influenced the perceived usefulness (explanatory power $29.6 \%$ of variation). The details of the lower limit confidence interval (LLCI) and upper limit confidence interval (ULCI) are given in Table 4. Among the above, mobility and post popularity were insufficient. In other words, the users perceived the videos from YouTuber usefulness is impacted by free of time, place, and well-connected of system characteristics with high absence from reality about the videos from YouTuber of specific characteristic. Thus, hypotheses 2, 4, and 5 were supported for perceived usefulness (extrinsic motivation). Then, users felt that the escapism $(\beta=0.371, t=7.217, \mathrm{p}<0.001)$ and usefulness $(\beta=0.171$, $\mathrm{t}=3.341, \mathrm{p}<0.01$ ) influenced the entertainment value (explanatory power $21.4 \%$ of variation), in which the LLCI and ULCI did not contain zero. In other words, the users thought the videos from YouTuber were able to take them off reality and relax them. Thus, hypotheses 7 and 8 were supported for entertainment value (intrinsic motivation). Finally, the users feel that the usefulness $(\beta=0.278, \mathrm{t}=6.267, \mathrm{p}<0.001)$, entertainment value $(\beta=0.228$, $\mathrm{t}=4.939, \mathrm{p}<0.05)$, and post popularity $(\beta=0.354, \mathrm{t}=7.834, \mathrm{p}<0.001)$ influenced their preference, and the UUCI and ULCI did not also contain zero. Evidently, the more users perceive they would be relieved or informed from the video of YouTuber and the more the likes, comments, shares, and response comments of video from YouTubers, the more they preferences are. Therefore, hypotheses 9,10, and 11 were supported for preference.

The mediating model was then examined using the bootstrapping approach. This study used the direct effect of escapism (95\% CI: 0.314 to 0.479$)$ and perceived usefulness (95\% CI: 0.097 to 0.238 ), which did not contain zero, and the indirect effect of escapism $(95 \% \mathrm{CI}$ : 0.023 to 0.111 ) and perceived usefulness (95\% CI: 0.004 to 0.053$)$ on preference through entertainment value, which did not also contain zero. Thus, the bootstrapping approach agreed that users' entertainment value have partial mediating effects of escapism and perceived usefulness on their preferences. Therefore, hypothesis 12 is supported. 
Table 4. hypotheses evaluation

\begin{tabular}{|c|c|c|c|c|c|c|}
\hline $\begin{array}{l}\text { dependent } \\
\text { variable }\end{array}$ & $\begin{array}{c}\text { independent } \\
\text { variable }\end{array}$ & Beta & $\mathrm{t}$ & $\mathrm{p}$ & LLCI & ULCI \\
\hline $\begin{array}{l}\text { perceived } \\
\text { usefulness }\end{array}$ & mobility & 0.088 & 1.895 & 0.072 & -0.011 & $0.154 \mathrm{H} 1$ not supported \\
\hline $\mathrm{R}^{2}=0.296$ & reachability & 0.315 & 6.350 & 0.000 & 0.210 & $0.404 \mathrm{H} 2$ supported \\
\hline $\mathrm{F}=23.910$ & compatibility & 0.068 & 1.469 & 0.143 & -0.033 & $0.121 \mathrm{H} 3$ not supported \\
\hline \multirow[t]{3}{*}{$\mathrm{p}=0.000$} & convenience & 0.133 & 2.568 & 0.011 & 0.013 & $0.165 \mathrm{H} 4$ supported \\
\hline & escapism & 0.212 & 3.743 & 0.000 & 0.088 & 0.343 H5 supported \\
\hline & post popularity & 0.012 & 0.234 & 0.815 & -0.07 & 0.089 H6 not supported \\
\hline entertainment & escapism & 0.371 & 7.217 & 0.000 & 0.004 & $0.225 \mathrm{H} 7$ supported \\
\hline $\mathrm{R}^{2}=0.214$ & usefulness & 0.171 & 3.341 & 0.001 & 0.079 & $0.222 \mathrm{H} 8$ supported \\
\hline \multicolumn{7}{|l|}{$\mathrm{F}=47.119$} \\
\hline \multicolumn{7}{|l|}{$\mathrm{p}=0.000$} \\
\hline preference & usefulness & 0.278 & 6.267 & 0.000 & 0.079 & $0.222 \mathrm{H} 9$ supported \\
\hline $\mathrm{R}^{2}=0.397$ & entertainment & 0.228 & 4.939 & 0.019 & 0.012 & 0.133 H10 supported \\
\hline $\begin{array}{l}F=75.584 \\
p=0.000\end{array}$ & post popularity & 0.354 & 7.834 & 0.000 & 0.097 & 0.190 H11 supported \\
\hline
\end{tabular}

\section{Conclusion}

\subsection{Discussion and Contribution}

On the basis of previous studies, a mediated model was developed in this study to explore the relationships among system characteristics, YouTuber specific characteristics, motivation theory, and preference about the videos from YouTubers. The main objective of this study is to determine the factors that affect the users' preferences about YouTubers. To realize this, a research model was proposed which consists of four system characteristics, two YouTuber specific characteristics, two intrinsic and extrinsic motivations, and one preference for dependent variable. The major contributions of this study are as follows. First, this study successfully extended the motivation theory to a context of YouTuber preferences, which is different from the other IT contexts. This study combines the system characteristics and YouTuber specific characteristics, which are related to the videos from YouTuber and have been ignored in previous studies. The validated questionnaire will be useful to researchers in further developing and refining free platform research models, as well as to managers in developing effective platform service systems, such as comparison websites or purchase platforms.

The empirical analysis results showed that system characteristics (reachability and convenience), and YouTuber specific characteristics (escapism) are critical determinants of the perceived usefulness of YouTube. Among these factors, reachability is the most powerful factor to influence usefulness. Mobility and compatibility have insignificant effects on 
perceived usefulness, which agree with the results of Hossain et al. (2018) and Kim et al. (2010) and, however, disagree with the results of Li et al. (2014) and Yen and $\mathrm{Wu}$ (2016). This is probably the respondents' present thoughts; therefore, this result needs to explored further. On the other hand, the result strongly confirms that perceived usefulness and escapism are the predictive powers of the entertainment value. Finally, perceived usefulness, post popularity, and entertainment value were significant factors affecting user preference. Users' entertainment value was found to have a partial mediating role for both escapism and usefulness on preference. The specific characteristics of YouTubers (escapism) and extrinsic motivation (perceived usefulness) exert immediate effects on preference as well as indirect effects via intrinsic motivation (entertainment value). System and specific features and motivation are also thought to play vital roles in the preference of videos from YouTubers. The post popularity also plays an essential role in influencing user preference. In the literature, post popularity was found to directly influence usefulness and preferences in social media marketing (Chang et al., 2015) and mobile payment (Kim et al., 2015). However, the result of the present study, which considers a free platform service, quite differs from those of studies. The result provides the factors that influences the continuous choice YouTuber' videos. As free technologies advance, the service providers can enhance the reachable and convenient system with additional enjoyable videos by exploiting the omnipresent technologies, thus resulting in greater usefulness. Nowadays, many users hope to be famous; therefore, the famous YouTubers have to post innovative and interesting ideas to continue captivating users.

\subsection{Implications and Practice for Research}

The findings of this study have significant implications for the development and refinement of free platforms. Considering that YouTubers are required to render significant relieving and informative contributions, it is still very important for YouTubers to ensure they have special users' preferences. To achieve this, appropriate famous contributors' business model as well as system designs should be developed. From the managerial perspective, the findings of this research should be considerably helpful in maintaining a series of chains in YouTube, such as merchants who buy ad to choose the higher impact videos of YouTubers, advertisers who create ad. to make people relax and interesting, mobile network designers who design the network accessible, maintainers who debug the problems to let people watch the videos smoothly, YouTubers who provide appropriate videos to post innovative and interesting ideas to make users relax or share knowledge, and users who choose the videos to fit new requirements and solve problems. From the academic perspective, an attempt was made to classify system characteristics and specific characteristics relating to motivation and preference and integrate them into the proposed research model. In the future, researchers should be able to use these constructs readily to validate services on free platforms.

\subsection{Limitations and Future Research}

In addition, this study guides directions for future research regarding the system characteristics and innovation specific characteristics of platforms. However, this study also has limitations. First, intention was not incorporated into this proposed model. However, 
empirical supports exist, regarding the causal link between preference and intentions of shares and likes (Chang et al., 2015). This is worth adding the intention further. Second, other individual differences, such as personal innovativeness and knowledge (Kim et al., 2010), and special system characteristics variables may exist that can affect the YouTubers' preferences. Other system characteristics suggested in previous studies include ubiquity and privacy (Lin et al., 2011) to be suitable this situation; these should be further studied. Finally, the criteria for users' perception on mobility and compatibility of system characteristic did not sufficiently influence usefulness; it should be further investigated. Despite the abovementioned limitations, this paper improves the understanding of the YouTubers preferences and will provide a useful set of guidelines for the delivery of free and collaborated services to satisfy users.

\section{References}

Amabile, T. M. (1993). Motivational synergy: Toward new conceptualizations of intrinsic and extrinsic motivation in the workplace. Human resource management review, 3(3), 185-201. https://doi.org/10.1016/1053-4822(93)90012-S

Arvidsson, N. (2014). Consumer attitudes on mobile payment services - results from a proof of concept test. Int. J. Bank Mark., 32(2), 150-170. https://doi.org/10.1108/IJBM-05-2013-0048

Asraar, A. K. A. (2015). Utilitarian and hedonic motives of university students in their online shopping-A gender based examination. Global Management Review, 9(4), 75-91.

Au, Y. A., \& Kauffman, R. J. (2008). The economics of mobile payments: Understanding stakeholder issues for an emerging financial technology application. Electronic Commerce Research and Applications, 7(2), 141-164. https://doi.org/10.1016/j.elerap.2006.12.004

Bhattacherjee, A., \& Premkumar, G. (2004). Understanding changes in belief and attitude toward information technology usage: A theoretical model and longitudinal test. MIS Quarterly, 28(2), 229-254. https://doi.org/10.2307/25148634

Bhattacherjee, A., \& Sanford, C. (2006). Influence processes for information technology acceptance: An elaboration likelihood model. MIS Quarterly, 30(4), 805-825. https://doi.org/10.2307/25148755

Chang, Y. T., Yu, H., \& Lu, H. P. (2015). Persuasive messages, popularity cohesion, and message diffusion in social media marketing. Journal of Business Research, 68(4), 777-782. https://doi.org/10.1016/j.jbusres.2014.11.027

Correa, T., Hinsley, A. W., \& De Zuniga, H. G. (2010). Who interacts on the Web? The intersection of users' personality and social media use. Computers in Human Behavior, 26(2), 247-253. https://doi.org/10.1016/j.chb.2009.09.003

Cronin, J. J., Brady, M. K., \& Hult, G. T. M. (2000). Assessing the effects of quality, value, and customer satisfaction on consumer behavioral intentions in service environments. Journal of retailing, 76(2), 193-218. https://doi.org/10.1016/S0022-4359(00)00028-2 
Daskapan, S., Van den Berg, J., \& Ali-Eldin, A. (2010). Towards a trustworthy short-range mobile payment system. Int. J. Inf. Technol. Manag., 9(3) 317-336. https://doi.org/10.1504/IJITM.2010.030947

Davis, F. D., Bagozzi, R. P., \& Warshaw, P. R. (1989). User acceptance of computer technology: A comparison of two theoretical models. Management Science, 35(8), 982-1003. https://doi.org/10.1287/mnsc.35.8.982

De Vriesa, L., Gensler, S., \& Leeflang, P. S. H. (2012). Popularity of brand posts on brand fan pages: An investigation of the effects of social media marketing. Journal of Interactive Marketing, 26(2), 83-91. https://doi.org/10.1016/j.intmar.2012.01.003

Deci, E. L., \& Ryan, R. M. (1985). The general causality orientations scale: Self-determination in personality. Journal of research in personality, 19(2), 109-134. https://doi.org/10.1016/0092-6566(85)90023-6

Dong, X., Chang, Y., Wang, Y., \& Yan, J. (2017). Understanding usage of Internet of Things (IOT) systems in China: Cognitive experience and affect experience as moderator. Information Technology \& People, 30(1), 117-138. https://doi.org/10.1108/ITP-11-2015-0272

Fornell, C., \& Larcker, D. F. (1981). Evaluating structural equation models with unobservables and measurement error. Journal of Marketing Research, 18(1), 39-50. https://doi.org/10.1177/002224378101800104

Gilbert, R. L., Murphy, N. A., \& Avalos, M. C. (2011). Realism, idealization, and potential negative impact of 3D virtual relationships. Computers in Human Behavior, 27(5), 2039-2046. https://doi.org/10.1016/j.chb.2011.05.011

Grant, M. M. (2004). Learning to teach with the web: Factors influencing teacher education faculty. The Internet and higher education, 7(4), 329-341. https://doi.org/10.1016/j.iheduc.2004.09.005

Hair, J. F., Anderson, R. E., Tatham, R. L., \& Black, W. C. (1998). Multivariate data analysis. Englewood Cliffs, NJ: Prentice Hall International.

Hayes, A. F. (2018). Partial, conditional, and moderated mediation: Quantification, inference, and interpretation. Communication Monographs, 85(1), 4-40. https://doi.org/10.1080/03637751.2017.1352100

Hayes, A. F., \& Preacher, K. J. (2014). Statistical mediation analysis with a multicategorical independent variable. British Journal of Mathematical and Statistical Psychology, 67(3), 451-470. https://doi.org/10.1111/bmsp.12028

Henning, B., \& Vorderer, P. (2001). Psychological escapism: Predicting the amount of television viewing by need for cognition. Journal of Communication, 51(1), 100-120. https://doi.org/10.1111/j.1460-2466.2001.tb02874.x

Hirschman, E. C. (1983). Aesthetics, ideologies and the limits of the marketing concept. The journal of marketing, 47(3), 45-55. https://doi.org/10.1177/002224298304700306 


\section{Macrothink}

International Journal of Human Resource Studies

ISSN 2162-3058

2019, Vol. 9, No. 1

Hossain, M. A., Hossain, M. S., \& Jahan, N. (2018). Predicting continuance usage intention of mobile payment: An experimental study of bangladeshi customers. Asian Economic and Financial Review, 8(4), 487-498.

Hsu, C. L., \& Lin, J. C. C. (2008). Acceptance of blog usage: The roles of technology acceptance, social influence and knowledge sharing motivation. Information \& management, 45(1), 65-74. https://doi.org/10.1016/j.im.2007.11.001

Huizinga, J. (1955). Homo ludens: A study of the play element in culture, The Beacon Press, Boston, MA.

Johnson, D. H. (1980). The comparison of usage and availability measurements for evaluating resource preference. Ecology, 61(1), 65-71. https://doi.org/10.2307/1937156

Joiner, T. A. (2001). The influence of national culture and organizational culture alignment on job stress and performance: evidence from Greece. Journal of Managerial Psychology, 16(3), 229-242. https://doi.org/10.1108/02683940110385776

Jung, Y., \& Kang, H. (2010). User goals in social virtual worlds: A means-end chain approach. Computers in Human Behavior, 26(2), 218-225. https://doi.org/10.1016/j.chb.2009.10.002

Kim, C., Mirusmonov, M., \& Lee, I. (2010). An empirical examination of factors influencing the intention to use mobile payment. Computers in Human Behavior, 26(3), 310-322. https://doi.org/10.1016/j.chb.2009.10.013

Kim, H. Y., \& Kim, Y. K. (2005). Escapism, consumer lock in, attitude, and purchase: An illustration from an online shopping context. Journal of Shopping Center Research, 12(2), 103-115.

Kim, S. S., \& Son, J. Y. (2009). Out of dedication or constraint? A dual model of postadoption phenomena and its empirical test in the content of online services. MIS Quarterly, 33(1), 49-70. https://doi.org/10.2307/20650278

Li, H., Liu, Y., \& Heikkilä, J. (2014). Understanding the factors driving NFC-enabled mobile payment adoption: An empirical investigation. In PACIS (p. 231).

Lim, A. S. (2007). Inter-consortia battles in mobile payments standardization. Electronic Commerce Research and Applications, 2(2), 15-23.

Lin, J., Lu, Y., Wang, B., \& Wei, K. K. (2011). The role of inter-channel trust transfer in establishing mobile commerce trust. Electronic Commerce Research and Applications, 10(6), 615-625. https://doi.org/10.1016/j.elerap.2011.07.008

Mallat, N. (2007). Exploring consumer adoption of mobile payments-A qualitative study. The Journal of Strategic Information Systems, 16(4), 413-432. https://doi.org/10.1016/j.jsis.2007.08.001

Mathwick, C., Malhotra, N., \& Rigdon, E. (2001). Experiential value: conceptualization, measurement and application in the catalog and Internet shopping environment. Journal of retailing, 77(1), 39-56. https://doi.org/10.1016/S0022-4359(00)00045-2 


\section{Macrothink}

International Journal of Human Resource Studies

ISSN 2162-3058 2019, Vol. 9, No. 1

McRoberts, L. M., Paczkowski, L. W., \& Rondeau, D. E. (2016). U.S. Patent No. 9,282,898. Washington, DC: U.S. Patent and Trademark Office.

Nunnally J. C., \& Bernstein, I. H. (1994). Psychometric Theory, McGraw-Hill, New York, NY.

Overby, J. W., \& Lee, E. J. (2006). The effects of utilitarian and hedonic online shopping value on consumer preference and intentions. Journal of Business research, 59(10), 1160-1166. https://doi.org/10.1016/j.jbusres.2006.03.008

Park, D. H., \& Kim, S. (2008). The effects of consumer knowledge on message processing of electronic word-of-mouth via online consumer reviews. Electronic Commerce Research and Applications, 7(4), 399-410. https://doi.org/10.1016/j.elerap.2007.12.001

Park, E., Sung, J., \& Cho, K. (2015). Reading experiences influencing the acceptance of e-book devices. The Electronic Library, 33(1), 120-135. https://doi.org/10.1108/EL-05-2012-0045

Perea y Monsuwé, T., Dellaert, B. G., \& De Ruyter, K. (2004). What drives consumers to shop online? A literature review. International journal of service industry management, 15(1), 102-121. https://doi.org/10.1108/09564230410523358

Preacher, K. J., \& Hayes, A. F. (2004). SPSS and SAS procedures for estimating indirect effects in simple mediation models. Behavior research methods, 36(4), 717-731. https://doi.org/10.3758/BF03206553

Ramos-Serrano, M., \& Herrero-Diz, P. (2016). Unboxing and brands: YouTubers phenomenon through the case study of Evantubehd. Revista Prisma Social, 90-120.

Ryan, R. M., \& Deci, E. L. (2000a). Self-determination theory and the facilitation of intrinsic motivation, social development, and well-being. American Psychologist, 55(1), 68-78. https://doi.org/10.1037/0003-066X.55.1.68

Ryan, R. M., \& Deci, E. L. (2000b). Intrinsic and extrinsic motivations: Classic definitions and new directions. Contemporary Educational Psychology, 25(1), 54-67. https://doi.org/10.1006/ceps.1999.1020

Saade, R., \& Bahli, B. (2005). The impact of cognitive absorption on perceived usefulness and perceived ease of use in on-line learning: An extension of the technology acceptance model. Information and Management, 42(2), 317-327. https://doi.org/10.1016/j.im.2003.12.013

Sethi, V., \& King, W. R. (1994). Development of measures to assess the extent to which an information technology application provides competitive advantage. Management science, 40(12), 1601-1627. https://doi.org/10.1287/mnsc.40.12.1601

Siklander, P., Kangas, M., Ruhalahti, S., \& Korva, S. (2017). Exploring triggers for arousing interest in the online learning. In Proceedings of the 11th Annual International Technology, 
Education and Development Conference, INTED2017 (pp. 9081-9089). https://doi.org/10.21125/inted.2017.2150

Sinclair, R. C., Moore, S. E., Mark, M. M., Soldat, A. S., \& Lavis, C. A. (2010). Incidental moods, source likeability, and persuasion: Liking motivates message elaboration in happy people. Cognition and Emotion, 24(6), 940-961. https://doi.org/10.1080/02699930903000206

Smith, P., \& Sankaranarayanan, S. (2012). Smart agent based mobile shopping and secured payment. Int. J. Emerg. Trends Technol. Comput. Sci., 1(3), 240-254.

Teo, A. C., Tan, W. H., Keng-Boon, O., Teck-Soon, H., King-Tak, Y. (2015). The effects of convenience and speed in m-payment. Ind. Manag. Data Syst., 115(2), 311-331. https://doi.org/10.1108/IMDS-08-2014-0231

Trakulmaykee, N., SuhaimiBaharudin, A., Low, R. Q., \& Arshad, M. R. M. (2013). Investigating determinants of tourist intention and associations of perceived usefulness, ease of use and mobility in the context of mobile tourism guide. International journal of accounting and business management, 1(1), 123-130.

Vallerand, R. J. (1997). Toward a hierarchical model of intrinsic and extrinsic motivation. In Advances in experimental social psychology (Vol. 29, pp. 271-360). Academic Press. https://doi.org/10.1016/S0065-2601(08)60019-2

Venkatesh, V. (1999). Creation of favorable user perceptions: exploring the role of intrinsic motivation. MIS quarterly, 23(2), 239-260. https://doi.org/10.2307/249753

Verhagen, T., Feldberg, F., van den Hooff, B., Meents, S., \& Merikivi, J. (2012). Understanding users' motivations to engage in virtual worlds: A multipurpose model and empirical testing. Computers in Human Behavior, 28(2), 484-495. https://doi.org/10.1016/j.chb.2011.10.020

Wang, S. T. (2013). The influence of visual packaging design on perceived food product quality, value, and brand preference. International Journal of Retail \& Distribution Management, 41(10), 805-816. https://doi.org/10.1108/IJRDM-12-2012-0113

Westenberg, W. (2016). The influence of YouTubers on teenagers. Ensenada: University of TWENTE. https://essay.utwente.n1/71094/1/Westenberg_MA_BMS.pdf.

Wong A., \& Dean, A. (2009). Enhancing value for Chinese shoppers: The contribution of store and customer characteristics. Journal of Retailing and Consumer Services, 16(2), 123-134. https://doi.org/10.1016/j.jretconser.2008.11.004

Xu, Z., Turel, O., \& Yuan, Y. (2012). Online game addiction among adolescents: motivation and prevention factors. European Journal of Information Systems, 21(3), 321-340. https://doi.org/10.1057/ejis.2011.56

Yang, S., Lu, Y., Gupta, S., Caso, Y., and Zhang, R. (2012). Mobile payment services adoption across time: an empirical study of the effects of behavioral beliefs, social influences, 


\section{Macrothink}

International Journal of Human Resource Studies

ISSN 2162-3058 2019, Vol. 9, No. 1

and personal traits. Computer in Human Behavior, 28(1), 129-142. https://doi.org/10.1016/j.chb.2011.08.019

Yen, Y. S., \& Wu, F. S. (2016). Predicting the adoption of mobile financial services: The impacts of perceived mobility and personal habit. Computers in Human Behavior, 65, 31-42. https://doi.org/10.1016/j.chb.2016.08.017

Ylitalo, J. (2009). Controlling for common method variance with partial least squares path modeling. http://salserver.org.aalto.fi/vanhat_sivut/Opinnot/Mat-2.4108/pdf-files/eyli09b.pdf.

Zhang, X., de Pablos, P. O., Wang, X., Wang, W., Sun, Y., \& She, J. (2014). Understanding the users' continuous adoption of 3D social virtual world in China: A comparative case study. Computers in Human Behavior, 35, 578-585. https://doi.org/10.1016/j.chb.2014.02.034

Zhou, T. (2014). Understanding the determ inants of mobile payment continuance usage. Ind. Manag. Data Syst., 114(6), 936-948. https://doi.org/10.1108/IMDS-02-2014-0068

\section{Appendix}

Mobility (three items from Kim et al. (2010) to indicate the degree of people feelings about the videos from the YouTuber, seven-point Likert type scale)

1. I believe the videos from the YouTuber are independent of time.

2. I believe the videos from the YouTuber are independent of place.

3. I can watch the videos from the YouTuber anytime while need.

Reachability (three items from Kim et al. (2010) to indicate the degree of people feelings about the videos from the YouTuber, seven-point Likert type scale)

1. In general, I would be always reachable videos through the YouTuber.

2. Watching the videos from the YouTuber can be connected regardless of the location.

3. It is always possible for my need to watching the videos from the YouTuber.

Compatibility (three items from Kim et al. (2010) to indicate the degree of people feelings about the videos from YouTuber, seven-point Likert type scale)

1. I believe the videos from the YouTuber are compatible with existing technology.

2. I believe the videos from the YouTuber are compatible with other mobile services.

3. I believe the videos from the YouTube are compatible with my daily routine. 


\section{Macrothink}

International Journal of Human Resource Studies

ISSN 2162-3058 2019, Vol. 9, No. 1

Convenience (three items from Kim et al. (2010) to indicate the degree of people feelings about the videos from YouTuber, seven-point Likert type scale)

1. Watching the videos from the YouTuber is convenient.

2. The videos from the YouTuber are convenient because I can use them anytime.

3. The videos from the YouTuber are convenient because I can use it in any situation.

Perceived usefulness (three items from Kim et al. (2010) to indicate the degree of people feelings about the videos from the YouTuber, seven-point Likert type scale)

1. Watching the videos from the YouTuber would enable me to release or learn more quickly.

2. Watching the videos from the YouTuber makes it easier for me to release or learn.

3. I would find watching the videos from the YouTuber a useful relax or learning.

Escapism (four items from Verhagen et al., 2012 to indicate the degree of people feelings about the videos from the YouTuber, seven-point Likert type scale)

1. Watching the videos from the YouTuber makes me feel like I am in another world.

2. Watching the videos from the YouTuber gets me away from it all.

3. I get so involved when I watch the videos from the YouTuber that I forget everything else.

4. Watching the videos from the YouTuber truly feels like an escape.

Post popularity (three items from Chang et al. (2015) to indicate the degree of people feelings about the videos from the YouTuber, seven-point Likert type scale)

1. I think responses with more people pressing like, sharing, and responding positively are trustworthy of the videos from the YouTuber.

2. I think responses with more people pressing like, sharing, and responding positively are reliable of the videos from the YouTuber.

3. I think responses with more people pressing like, sharing, and responding positively are believable of the videos from the YouTuber. 


\section{Macrothink}

International Journal of Human Resource Studies

ISSN 2162-3058 2019, Vol. 9, No. 1

Entertainment value (three items from Verhagen et al. (2012) to indicate the degree of people feelings about the videos from the YouTuber, seven-point Likert type scale)

1. I think videos posts from the YouTuber are very entertaining.

2. The enthusiasm of videos from the YouTuber are catching, it picks me up.

3. Watching videos posts from the YouTuber do entertain me.

Preference (three items from Chang et al. (2015) to indicate the degree of people feelings about the videos from the YouTuber, seven-point Likert type scale)

1. I feel pleasant when watching videos posts from the YouTuber.

2. I feel good when finding videos posts from the YouTuber.

3. I like browsing videos posts from the YouTuber.

\section{Copyright Disclaimer}

Copyright for this article is retained by the author(s), with first publication rights granted to the journal.

This is an open-access article distributed under the terms and conditions of the Creative Commons Attribution license (http://creativecommons.org/licenses/by/4.0/). 